\title{
Violencias simbólicas en la provincia de Márquez, departamento de Boyacá, Colombia
}

\author{
Symbolic violence in the province of Marquez, department of \\ Boyacá, Colombia
}

https://doi.org/10.15332/iust.v0i15.2085

\section{Jhon Fredy Pérez-Rivera}

Licenciado en Ciencias Sociales y Magister (C) en Historia de la Universidad Pedagógica y Tecnológica de Colombia Correo electrónico: fredyp24@hotmail.com

\section{Resumen}

El siguiente artículo es fruto de una investigación con fuentes de archivo, en el que se busca determinar la manera en que en la Provincia de Márquez, departamento de Boyacá, se vivió el conflicto político bipartidista durante lo que se conoce como la Época de la Violencia (1946-1953). Sin embargo, a pesar de que el tema que comúnmente se narra cuando de este período de la historia de Colombia se trata es el de la violencia traducida en asesinatos, la temática central de esta investigación será lo que se ha denominado, violencias simbólicas, es decir, aquellas que sin causar un daño físico, sí atentaban contra la dignidad y la libertad de las personas.

Palabras clave: Violencia simbólica, política, conflicto, estigmas, comunismo, bandoleros, elecciones.

\begin{abstract}
The following article is the result of an investigation with archival sources, in which the aim is to determine how in the Province of Márquez, department of Boyacá, the bipartisan political conflict was experienced during what is known as the Time of the Violence (1946-1953). However, despite the fact that the topic that is commonly narrated when this period of Colombian history is about violence is translated into murders, the central theme of this investigation will be what has been called, as symbolic violence, that is, those that without causing physical damage, did attempt against the dignity and freedom of the people.
\end{abstract}

Keywords: Symbolic violence, politics, conflict, stigmas, communism, bandits, elections.

\section{Résumé}

L'article suivant est le résultat d'une enquête avec des sources d'archives, dans laquelle le but est de déterminer comment dans la province de Márquez, département de Boyacá, le conflit politique bipartisan a été vécu au cours de ce qui est connu sous le nom de Violence (1946-1953). Cependant, en dépit du fait que le sujet qui est souvent raconté quand cette période de l'histoire colombienne est sur la violence est traduit en meurtres, le thème central de cette enquête sera ce qui a été appelé, comme violence symbolique c'est-à-dire ceux qui, sans causer de dommages physiques, ont porté atteinte à la dignité et à la liberté du peuple.

Mots clés: Violence symbolique, politique, conflit, stigmatisation, communisme, bandits, élections. 



\section{Violencias simbólicas en la provincia de Márquez, departamento de Boyacá, Colombia*}

Jhon Fredy Pérez-Rivera

\section{INTRODUCCIÓN}

La provincia de Márquez no fue ajena a la violencia vivida en el país, y aunque no tuvo lugar allí la confrontación abierta, entre conservadores y liberales, sí se presentó en este lugar la violencia propiciada por la exacerbación de los ánimos y los resentimientos partidistas, aquella violencia que se reprodujo a pequeña escala, es decir, la violencia verbal y, en no pocos casos, la física, entre pobladores de un mismo municipio, o las amenazas de agresiones entre habitantes de municipios cercanos principalmente propiciada a través del "rumor" de invasión, que producía en el otro municipio la reacción de alistamiento para la defensa, la zozobra y con esto la intolerancia hacia quienes fueran del partido minoritario.

\section{METODOLOGÍA}

En este orden se busca mostrar que la Violencia Simbólica se hizo presente en la provincia de Márquez; para este propósito, se inicia con una breve descripción del ideario conservador utilizado para conquistar afectos; muestra inicialmente la manera como los señalamientos, la información, los discursos y la propaganda eran utilizados como instrumento de poder; luego, mediante algunos casos, se ejemplifica cómo se dio el uso de estos en la provincia de Márquez para crear estigmas con el propósito de relacionar a los liberales con el sectarismo, el comunismo, el bandolerismo, el ateísmo, la delincuencia, al tiempo que se buscaba que los liberales se cambiaran de partido o simplemente no votaran en las elecciones. No obstante, se verá que prácticamente en todas las formas de violencia simbólica que aquí se describen, nuevamente la Iglesia católica y la religiosidad estarán presentes de forma directa o indirecta. Para este se tendrán en cuenta como fuentes de información básica, los periódicos conservadores regionales, los expedientes judiciales y algunos testimonios.

* Artículo de investigación resultado de la tesis de Maestría en Historia realizada en la Universidad Pedagógica y Tecnológica de Colombia. 


\section{LA PROVINCIA DE MÁRQUEZ 1946-1953}

La provincia de Márquez del departamento de Boyacá, ubicada en la vertiente de la cordillera que da hacia los Llanos Orientales, fue creada el 15 de julio de 1905 por el presidente Rafael Reyes en memoria de José Ignacio de Márquez, presidente de Colombia entre 1837 y 1841 y quien nació en Ramiriquí en 1793 (Pulido, 2010), capital de la provincia.

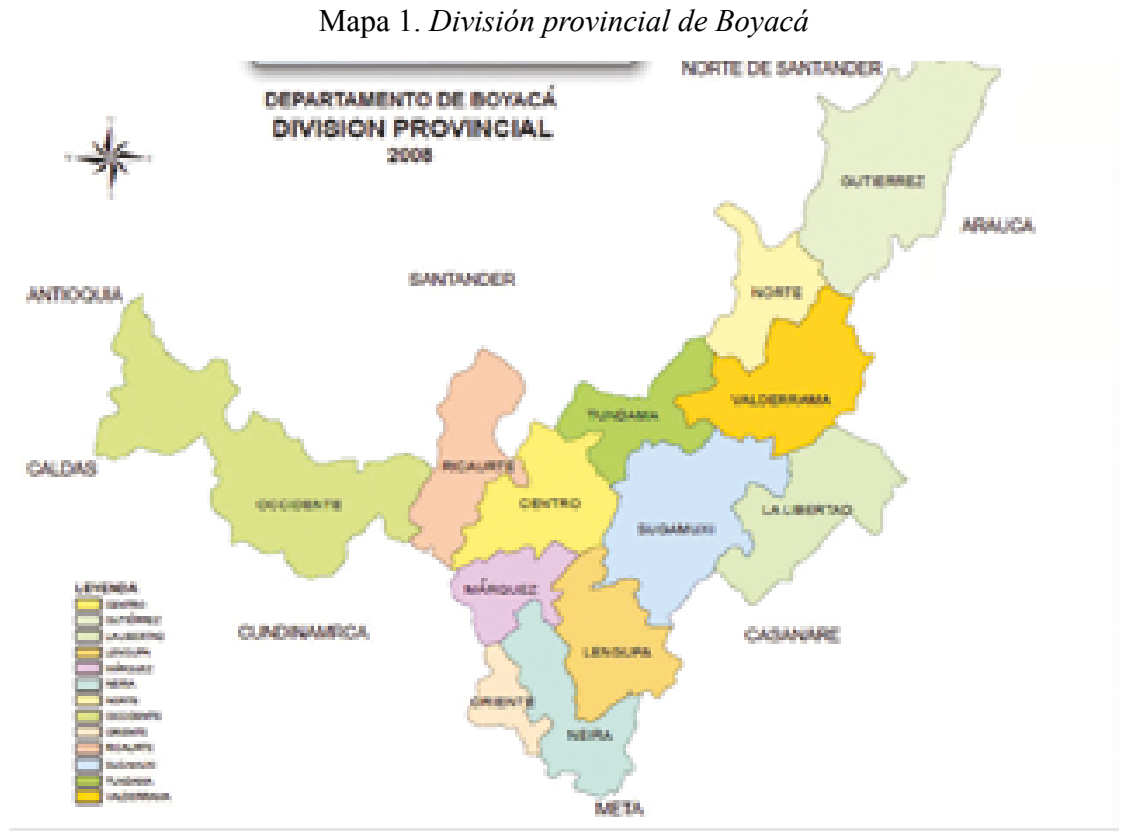

Fuente: Elaborado con base en: http://www.iecolria.edu.co/dia_de_boyaca.htm

\section{Características sociodemográficas de la provincia de Márquez}

Ahora bien, en los años cuarenta, la provincia de Márquez comprendía un territorio de 847 km2 (Contraloría General de la Nación, 1952), caracterizado por un relieve quebrado, ubicado entre los pisos térmico, frío y paramo, 2200 a $3400 \mathrm{msnm}$ (Pulido, 2010, p. 156), con campos de gran fertilidad que hacen parte de las cuencas de los ríos Garagoa y Lengupá. En los años 40, esta provincia estaba integrada por 
los municipios de Boyacá, Ciénega, Jenesano, Ramiriquí, Rondón, Tibaná, Úmbita y Viracachá, que luego fue ampliada con los municipios de Turmequé y Nuevo Colón.

Mapa 2. Municipios de la provincia de Márquez

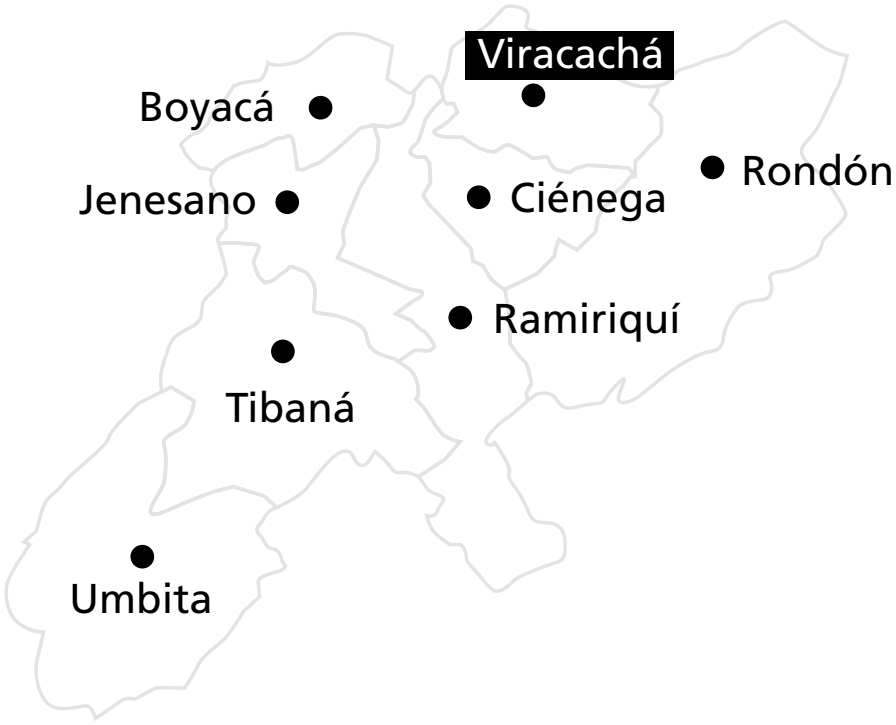

Fuente: Elaborado con base en: https://www.google.com.co/search?q=provincia+de+márquez

En la década de los 40 en la provincia de Márquez vivían 55.963 personas aproximadamente (Contraloría General de la Nación, 1952), de las cuales el 96\% habitaban el sector rural.

Tabla 1. Características demográficas de los municipios de la Provincia de Márquez

\begin{tabular}{|c|c|c|c|c|c|c|}
\hline Municipio & $\begin{array}{c}\text { Población } \\
\text { urbana } \\
\text { (cabecera) }\end{array}$ & $\begin{array}{c}\text { Población } \\
\text { rural }\end{array}$ & $\begin{array}{c}\text { Total } \\
\text { población }\end{array}$ & $\begin{array}{c}\text { Pobla- } \\
\text { ción } \\
\text { mayor de } \\
7 \text { años }\end{array}$ & $\begin{array}{c}\text { Saben } \\
\text { leer }\end{array}$ & $\begin{array}{l}\text { No saben } \\
\text { leer }\end{array}$ \\
\hline BOYACÁ & 370 & 7.588 & 7.958 & 5.828 & 1.547 & 4.281 \\
\hline CIÉNEGA & 292 & 4.153 & 4.445 & 3.605 & 1.200 & 2.405 \\
\hline JENESANO & 428 & 8.190 & 8.618 & 6.195 & 1.519 & 4.676 \\
\hline NUEVO COLÓN & 171 & 4.230 & 4.401 & 3.366 & 1.345 & 2.021 \\
\hline RAMIRIQUÍ & 835 & 7.076 & 8.011 & 6.426 & 1.959 & 4.467 \\
\hline RONDÓN & 386 & 3.785 & 4.171 & 3.421 & 1.051 & 2.370 \\
\hline
\end{tabular}




\begin{tabular}{lcccccc} 
TIBANÁ & 502 & 10.048 & 10.550 & 8.816 & 2.856 & 5.960 \\
TURMEQUÉ & 662 & 5.944 & 6.603 & 5.724 & 2.169 & 3.555 \\
ÚMBITA & 535 & 6.752 & 7.287 & 6.338 & 1.911 & 4.427 \\
VEN TA Q U E - & 244 & 6.500 & 6.744 & 7.375 & 3.329 & 4.046 \\
MADA & 550 & 4.363 & 4.913 & 3.645 & 1.477 & 2.168 \\
VIRACACHÁ & 3898 & 51965 & 55963 & 44274 & 13120 & 30654 \\
\hline TOTAL & &
\end{tabular}

Fuente: Contraloría General de la República, Dirección Nacional de Estadística, 1953.

Ninguno de los municipios superaba los 11.000 habitantes, y de estos la gran mayoría vivía en la zona rural; además, lo que se consideraba como zona urbana generalmente eran pequeños caseríos de los cuales el más grande era Ramiriquí con 835 habitantes (Contraloría General de la Nación, 1952).

En términos generales, el acceso a la educación era muy bajo, con altos índices de analfabetismo, más del 75\% (Contraloría General de la Nación, 1952) y muy bajo promedio de escolaridad entre quienes habían tenido acceso a esta. Apenas el $25 \%$ sabían leer y escribir y la mayoría había cursado cuanto más 1 o 2 años de escuela (Archivo Judicial Tunja, 1946-1953).

Los municipios de la provincia de Márquez carecían en aquella época de servicios de energía eléctrica, acueducto, alcantarillado y solo en algunos casos había plantas generadoras de energía que beneficiaban a muy pocas personas; 258 personas tenían acceso a energía eléctrica $(0.33 \%)$, la cual era generada por plantas eléctricas caceras; 353 tenían acceso a acueducto $(0.45 \%)$; 35 personas tenían algún acceso a canalización de aguas residuales (0.04\%) (Contraloría General de la Nación, 1952). Había un hospital, pero el servicio que se ofrecía era muy básico.

La economía de los municipios que conformaban la provincia estaba relacionada con la producción agrícola de papa, maíz, frijol, haba, arveja, hibia, nabo, ruba, arracacha, entre otros. La mayoría de la gente de esta comarca era de bajos recursos, algunos laboraban en sus propios cultivos y muchos otros como peones; además los cultivos tenían como propósito fundamental el autoabastecimiento (Junco, 1992), pues la comercialización era mínima debido a la falta de vías de comunicación y medios de transporte (Pulido, 2010), pues en aquella época apenas se estaban construyendo las primeras carreteras que pudieran unir a los municipios de la provincia, y a esta con Tunja y Bogotá (Archivo Departamental de Boyacá, 1946-1953).

\section{Condiciones partidistas de la provincia de Márquez}

Los municipios de la provincia de Márquez, de acuerdo con los resultados electorales y con la tradición política de sus habitantes, podían catalogarse como de mayorías liberales o conservadoras. Es así que dentro de los municipios liberales se 
tiene a Tibaná y Jenesano con población mayoritariamente perteneciente a este partido; de otro lado, se tenía a Ciénega, Viracachá, Úmbita y Rondón con una población mayoritariamente conservadora; Ramiriquí tenía más población conservadora sin ser absoluta esta mayoría; igual caso pasaba en Boyacá donde había más partidarios liberales pero sin ser hegemónico este partido.

Esta condición de mayorías liberales o conservadoras no variaría a lo largo del período estudiado (1946-1953), por el contrario, estas mayorías se hicieron más acentuadas, tanto en los municipios liberales como conservadores, circunstancia que generó tensiones, pequeñas migraciones y hasta conflictos por límites como se verá más adelante.

Mapa 3. Mayorías partidistas en los municipios de la provincia de Márquez

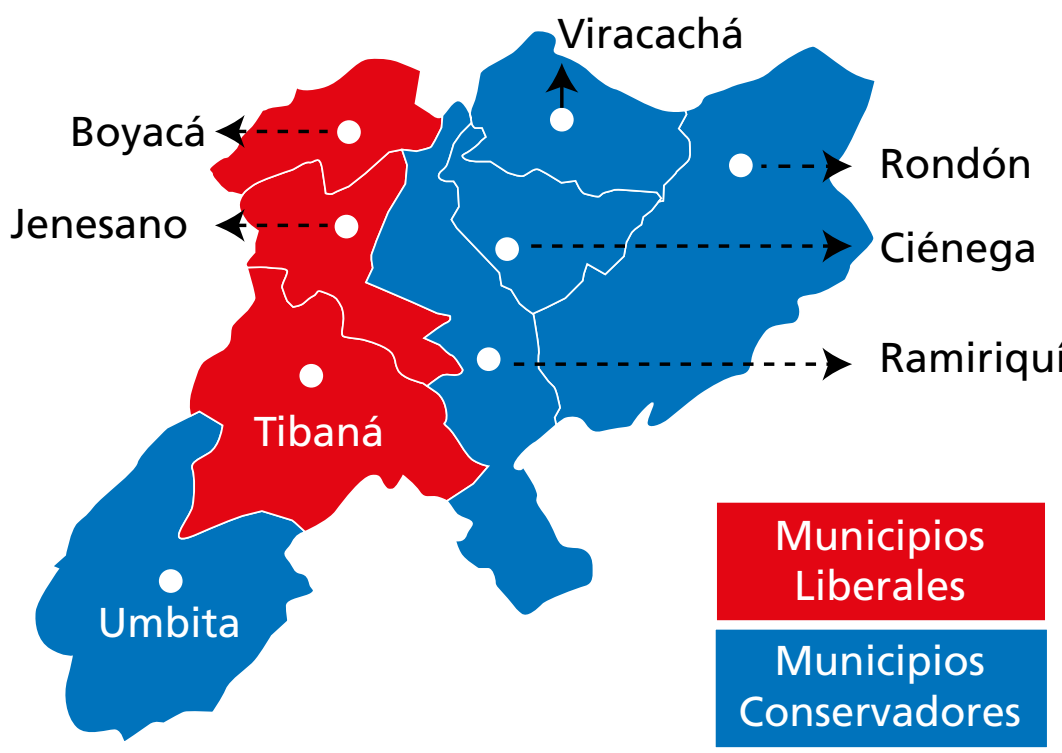

Fuente: Elaborado con base en la información de Junco (1992) y Rojas (1992).

\section{LAS VIOLENCIAS SIMBÓLICAS}

No solo a través de la violencia física se buscó vencer en esta contienda, también se hizo uso de otras formas de violencia caracterizadas por no atentar contra la integridad física o la vida de las personas, pero sí contra su buen nombre, sus decisiones o su dignidad. Es así que entre estas otras formas de violencia, fue destacada la relacionada con el uso de hostigamientos, de señalamientos y acusaciones, con el rechazo o la intolerancia, con la información y la propaganda 
mediante los cuales se procuraba estigmatizar al contendor político hasta lograr que quienes pertenecieran a este partido fueran vistos con odio, rabia, recelo, desconfianza o inclusive con desprecio, al tiempo que se buscaba impedir que los liberales fueran a las urnas o si lo hacían fuera en apoyo del partido conservador.

\section{La difusión de la exacerbación de los ánimos}

A pesar de que las hostilidades y los conflictos por las diferencias partidistas ya habían tenido manifestaciones durante los 16 años de la República liberal, a partir del año 1946, cuando el partido conservador vuelve al poder, el conflicto por el dominio del Estado comienza a hacerse cada vez más fuerte, pues este buscó a toda costa consolidarse en el poder, para lo cual debía, además de controlar el ejecutivo, también controlar la rama legislativa, razón por la que era necesario dominar el electorado para ganar las elecciones; en estas circunstancias, una estrategia y un instrumento de poder muy importante para el partido conservador iba a ser el de la información, el discurso y la propaganda, ya que debían buscar deslegitimar, amedrentar, estigmatizar y disuadir al pueblo liberal para reducirlos cuantitativamente con miras a las elecciones que de ahí en adelante se iban a realizar. Esta razón justificó acciones como la del Concejo de Rondón publicada en la prensa:

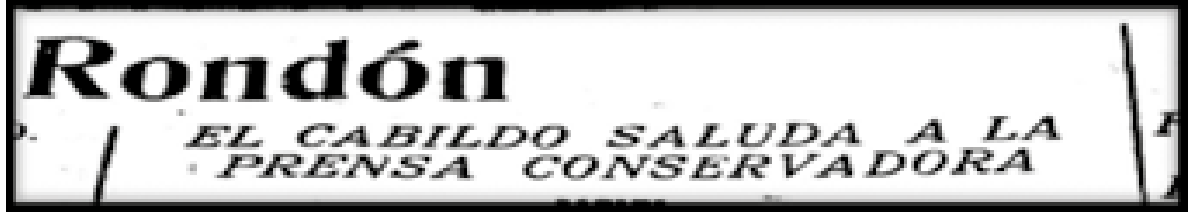

Fuente: El Demócrata, N. 28. Archivo Regional de Boyacá (ARB) 1947.

En este sentido Foucault decía que: "las relaciones de poder no pueden ni establecerse, ni funcionar sin los discursos. No hay ejercicio del poder posible, sin una cierta economía de los discursos: estamos sometidos a la verdad del poder" (Foucault, 1992, p. 34). Un principio aplicado por el partido conservador que tenía el poder, era que debía consolidarse en el gobierno e imponerse electoralmente, y para esto un instrumento o, mejor, un arma de importancia serían los discursos o la propaganda que, valiéndose de los medios a su alcance, deberían hacer llegar a la mayor cantidad de personas posible.

Pasar de las violencias verbales a las violencias fácticas era un hilo muy débil, y fue lo que en muchos lugares de Colombia, entre estos la provincia de Márquez, dejó como consecuencia a personas asesinadas en un camino, en una cantina, en una plaza, casi siempre después de haber recibido varias puñaladas o varios disparos de parte de un contrincante político, que bien podía ser su vecino e incluso su pariente, 
pero que pertenecía al partido contrario, lo que lo convertía en su enemigo. Muchos otros debieron irse de sus poblaciones de origen, o aceptar un cambio de partido y resignarse ante la hostilidad de autoridades civiles, militares y religiosas, e inclusive la de sus propios vecinos.

Lo vivido muestra que el partido que tenía el poder buscaba llevar a los colombianos al sectarismo enfermizo, al odio o al miedo respecto al partido contrario, había que mentalizarlo para defender su partido con firmeza y entereza. Esta lógica, que legitimaba la violencia para mantener el poder, justificándola mediante un discurso que defendía el statu quo, con ideas como la defensa de la religión católica, el mantenimiento del orden, la primacía de la patria, conceptos que, según la ideología conservadora, "estaban tocados de eternidad: Dios, patria y libertad (...), pues estos guardaban el secreto de la solución adecuada para todos los conflictos" (Oquist, 1978).

La élite conservadora se consideraba dueña de la verdad y de las soluciones para todos los problemas, pero estas ideas, repetidas muchas veces, aunadas a las ideas que a su vez venían del partido liberal, llevarían a que el ambiente político y social del país se fuera enrareciendo poco a poco hasta entrar en una lógica de violencia que aún hoy sigue presente.

En estas circunstancias, unos elementos muy explotados desde la prensa conservadora, con el propósito de estigmatizar a quienes apoyaban al partido liberal, fueron los del mantenimiento del orden y la defensa de la Patria, para lo cual se hizo gran énfasis en asociar al partido liberal con conceptos contrarios a aquellos preceptos como el bandolerismo, el comunismo, la persecución a la Iglesia, el sectarismo o la delincuencia. Se buscó crear una imagen negativa o perjudicial asociada a estos conceptos, convirtiéndolos en sinónimo de ateísmo, apostasía, herejía, despojo de la propiedad privada, revolución -en el sentido peyorativo de esta palabra- desorden, invasión de las ideas de Moscú, violencia y otros más, tratando de darle a cada uno de estos, de igual manera, la imagen más negativa posible.

A continuación se hace la descripción y el análisis de situaciones asociadas a la violencia simbólica relacionada con el uso de la información y con los estigmas políticos ocurridos en los municipios de la provincia de Márquez.

\section{La violencia simbólica se hace real}

\section{Violencia a través de los cargos públicos}

La rivalidad entre partidarios se trasladó al orden laboral. Fue muy común, por los hallazgos que se han realizado, encontrar manifestaciones de desprecio y de agresiones verbales hacia funcionarios que no pertenecían al partido en el poder presionando su renuncia, con el fin de reemplazarlos por partidarios conservadores. Pero también quejas de funcionarios que no cumplían con objetividad su labor e inclinaban decisiones o simplemente no cumplían con su función frente al ciudadano 
que consideraban pertenecía al otro partido. Los siguientes relatos y descripciones de casos sustentan lo anterior:

Con respecto a Ramiriquí en febrero de 1948 se afirma: "Jorge Arenas Ramírez por fin desocupa la beneficencia, lo remplaza el Dr. Agustín Borda Argüello" (El Demócrata, N. 48, 1948). A Arenas se le acusa de ser sectario y de haber permanecido todos los 16 años de gobierno liberal y de haber hecho lo que quiso con el hospital de Ramiriquí. La nota muestra cómo es percibido un cambio de funcionario y se celebra el hecho de poder ir remplazando en las entidades del Estado a los liberales por elementos del partido conservador. En el mismo sentido, otra información dice: "Mientras en Cundinamarca se destituyen a los maestros que tomaron parte en los sucesos del 9 de abril, en Boyacá son premiados por el director de Educación, Guillermo Alfredo Escobar, ascendiéndolos a inspectores" (El Demócrata, N. 37, 1948). Se reclama el hecho de que en Ramiriquí no se esté cambiando a los funcionarios liberales, en este caso los maestros, como sí se está haciendo en Cundinamarca. En fin, esto era también parte del conflicto bipartidista: el control del Estado, en el sentido de ocupar los puestos y cargos de la burocracia nacional.

En Boyacá, Boyacá se denuncia como "Pésima la administración de Justicia" ( $E l$ Demócrata, N. 62, 1948). Inicialmente parecería que se hiciera referencia a algún caso en el que se hubiese fallado judicialmente de manera arbitraria y sectaria, pero lo que se reclamaba era por el despido de un funcionario conservador ordenado por Manuel José Rodríguez, otro funcionario conservador, a quien acusan de traidor y le piden que no martirice más a los conservadores de este municipio. En el mismo sentido, se acusa a Julio Gómez, de quien dicen: "el eterno gamonal, en el régimen liberal mandó y desmandó aquí (en Boyacá) con sus correligionarios liberales y aún sigue mandando" (El Demócrata, N. 151, 1953). Esto permite ver cómo la disputa por los puestos y los cargos entre liberales y conservadores era muy fuerte, pues su control era determinante para imponerse finalmente en las elecciones y por ende en el poder, por esto se buscaba a través de la violencia dominar en este conflicto burocrático.

En Úmbita, otro de los municipios de la provincia de Márquez, caracterizado por su tendencia conservadora, se informó en la prensa sobre probables parcialidades en las decisiones tomadas en el juzgado municipal. La nota se originó luego de que una comisión de ciudadanos de ese pueblo visitara el periódico. La nota la presentó $E l$ Demócrata, así: 


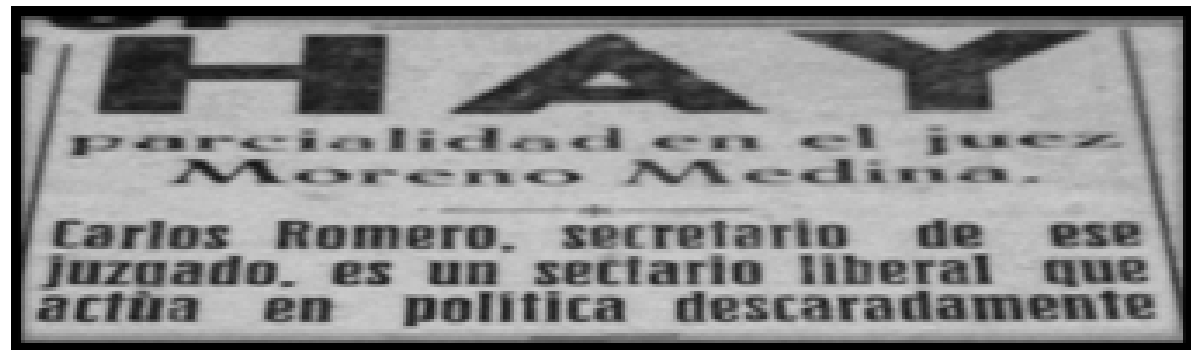

Fuente: El Demócrata, N. 95. (ARB), 1950.

Y en el desarrollo se comenta que:

Expresamente llegó a esta ciudad, en días pasados, una prestigiosa comisión de vecinos del municipio de Úmbita, para informar a este semanario, sobre la actitud sectaria asumida por el Juzgado que en esta ciudad sirve el abogado Cayetano Moreno Medina, quien tiene como secretario en ese centro de la injusticia, a un señor oriundo de Tibaná y que responde a nombre de Carlos Romero, de antecedentes delictuosos, toda vez que se le culpa de haber asesinado al ciudadano José del C. Gutiérrez, entre otros delitos. Los caballeros acusan graves irregularidades de sectarismo liberal efectuados en el juzgado del señor Moreno Medina, hablan de persecución a todo elemento que pertenezca al partido conservador (El Demócrata, N. $95,1950)$.

La situación de presunta arbitrariedad ocurre en 1950, motivada en el contexto de enfrentamiento bipartidista que sacudía al país. Luego no forman hechos aislados sino que fueron las manifestaciones de cómo llegó la violencia a muchos municipios del departamento. En este municipio se tenía ya otro antecedente con otro juez de nombre Juan Nepomuceno Sosa Amaya a quien se le había acusado en junio de ese mismo año, también de sectarismo (Expediente N. 2770, 1950). Dos jueces que en un mismo año fueron acusados de sectarismo político en favor del partido liberal dentro de un municipio conservador. Al primero lo habían cambiado por el segundo y de este también se solicitaba su destitución.

Las acusaciones de esta índole no solo se dieron en el orden institucional del Estado, sino que en algunos casos se elevó al orden eclesiástico, llevando a este nivel el enfrentamiento entre liberales y conservadores. Ejemplo de lo anterior se encuentra en una carta dirigida al Obispo de Tunja Crisanto Luque (Expediente N. 2770, 1950, pp. 14, 15), que describe una situación en la cual un sacerdote del municipio de Úmbita, aprovechándose de su investidura, amedrenta, amenaza, utiliza y reprime a un buen número de habitantes de este municipio. Acusan al párroco de tener a su disposición un grupo de personas, entre estas, unas mujeres que viven con él, que se prestan para hostigar a otras. Según los firmantes de la carta, el sacerdote crea un ambiente de violencia, tildando a unas personas de comunistas, amenazándolas con echarles 
la población encima, e incluso también llama comunistas a algunos miembros de la Utrabo ${ }^{1}$ por no entregarle un dinero que era parte de los recursos que manejaba este sindicato, y en general maltratando a los habitantes de la población cuando estos no obedecen sus disposiciones. Vemos en esta circunstancia la manera en que un sacerdote aprovechándose de su investidura maltrata inclusive a los de su mismo partido, calificándolos de comunistas cuando no actuaban conforme a sus designios.

Sin embargo, el suceso luego llega a niveles judiciales en contra del juez Juan Nepomuceno Sosa Amaya y de su secretario Rafael Sánchez (Expediente N. 2770, 1950, pp. 21-22), pues algunos de los firmantes de la carta en contra del sacerdote afirman que esta fue escrita por aquellos, quienes presionaron y engañaron a la gente para que firmaran el documento y que incluso en algunos casos, dicen ellos, sus firmas fueron suplantadas. Esta situación derivó en un proceso judicial en el que se vieron incursos el juez y su secretario a quienes se acusaba de favorecer los intereses del liberalismo, enfrentados al sacerdote a quien a su vez se había acusado de perseguir a los liberales. En este conflicto entre el juez y el sacerdote, terminará por dársele la razón al segundo, con el traslado del primero (Expediente N. 2770, 1950, p. 38).

Del enfrentamiento sectario entre los partidos no escaparon los responsables de la educación. Desde el periódico El Demócrata se habla de la existencia de "Maestros indeseables" (N. 16, 1947) refiriéndose a unos educadores liberales de la provincia de Márquez. Se habla de "una campaña depuradora" (El Demócrata, N. 16, 1947) que adelanta el semanario El Demócrata, en la que se mencionan nombres de maestros y las razones por las que se les descalifica y piden al público en general que "tomen atenta nota de quienes con sus ejemplos carecen de autoridad moral para orientar la niñez boyacense. Roberto Gamba, demos por caso, es un descreído, hasta masón, según él y pregonero ciego del régimen liberal desde 1937. Del corte del anterior, es Régulo Vargas de Viracachá y actual maestro en Turmequé" (N. 16, 1947).

Una situación muy similar se presenta con una docente del municipio de Boyacá, a quien el periódico califica como "una maestra sectaria" haciendo el siguiente comentario de desprecio y de odio por su filiación política:

Se ha confiado la escuela urbana a una maestra que escasamente sabe escribir su nombre pero que sí le sobra ciencia en materia política, pues lo único que enseña a sus alumnos es el significado del bello color "rosado" que según ella es el emblema liberal. También incita a las alumnas seguidoras suyas para que insulten a las compañeras hijas de conservadores premiando a las que lo hacen con escudos de Gaitán y con cintas rojas para que las prendan en sus uniformes (El Demócrata, N. 62, 1948).

"La administración de Mariano Ospina Pérez continuó la política de debilitamiento de los sindicatos beligerantes. Una nueva central obrera, la Unión de Trabajadores de Colombia (UTC), fue fundada en junio de 1946. La UTC, organizada por los jesuitas, respaldada por muchos industriales y favorecida por el gobierno conservador prosperó a expensas de la CTC" (Oquist, 1978) La UTRABO era la filial boyacense de la UTC. 
Una situación como esta, ya fuera cierta o no, era utilizada para hacer política, pero sobre todo para crear un sentimiento de intolerancia entre la gente.

Como se denota en las situaciones antes descritas, la libertad y el orden se mantenían sí y solo sí el poder, la autoridad, y los cargos del gobierno, eran ejercidos por militantes del partido conservador; por esto mismo, las instituciones, debían estar bajo su control para que su desempeño y sus decisiones fueran consideradas legítimas.

\section{Violencia a través de los estigmas políticos}

Dentro de las múltiples formas que asumió la violencia partidista de mediados del siglo XX y que se convirtió en una forma generalizada de expresión de las tensiones entre los dos partidos en todos los rincones del país, está el atropello verbal a través de la creación de estigmas, infundados generalmente pero que tuvieron como razón la de hacer ver al otro como el malo y como un peligro social, por esta razón, en este apartado, se describen cómo fueron utilizados en algunos municipios de la provincia de Márquez algunos de los prejuicios o estigmas con respecto a quienes eran liberales.

Uno de los calificativos más usados en forma negativa para descalificar a los liberales fue el de "bandoleros", palabra que usualmente describe a jefes o militantes de origen campesino, alzados en armas, como reacción a la cruzada antiliberal y anticomunista emprendida por parte del Gobierno mediante su aparato represivo. Estos debieron soportar un estrechamiento político o persecución, incluso dentro de su propio partido. Inicialmente, es decir, durante los años 1946 a 1953, eran considerados o calificados como bandoleros por parte del régimen gubernamental solamente los combatientes liberales (Sánchez y Meertens, 1983).

Pero este calificativo no solo se usó con respecto a aquellos hombres armados que cumplían con las anteriores características, sino que empezó a emplearse, desde la élite conservadora para referirse en general a los liberales con el propósito de estigmatizarlos asociándolos a estos personajes armados, que a su vez eran asimilados con las guerrillas, el comunismo, e inclusive con la delincuencia común, sobre todo la relacionada con el robo. Como un ejemplo de lo anterior, se tiene un caso con relación a Rondón en el que El Demócrata titulaba: "El bandolerismo infesta nuevamente la región. Los maleantes habían cesado durante la administración del doctor Villarreal" (El Demócrata, N. 49, 1948). Y en el desarrollo de la noticia se afirma que "Siendo Rondón la llave de seguridad que impide el alistamiento del comunismo de Lengupá, encabezado por Josué Rojas, el más vil de los hijos de la región, el actual gobernador no ha hecho nada y por el contrario destituyó al activo alcalde militar Luis A. Archila, dejando a la población a merced de los bandoleros que encabeza el conocido Rojas y su pandilla y además dejó sin policía al municipio" (El Demócrata, N. 49, 1948). 


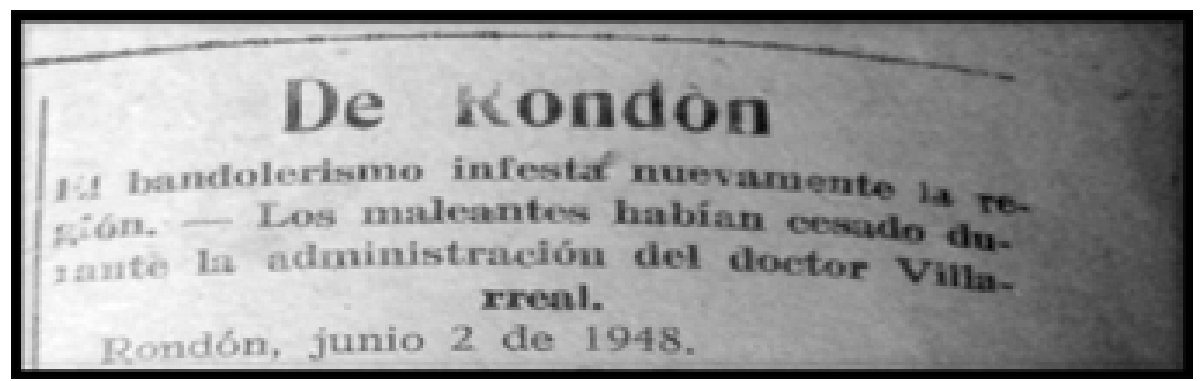

Fuente: El Demócrata, N. 49, ARB, 1948.

Aquí la palabra "bandolero" se usa como sinónimo de delincuente o maleante, pero a su vez se usa para referirse a los "comunistas" de Lengupá, de quienes se dice que estaban liderados por Josué Rojas, quien era oriundo de Rondón, y de quién se afirma reiteradamente era el principal bandolero de la Provincia de Márquez, y que por sus nexos con los bandoleros de Lengupá y de los Llanos podía ser una amenaza para el centro del departamento, por lo que se destaca el papel de Rondón como "llave de seguridad" para evitar una posible invasión. Sin embargo, en ningún documento se pudo corroborar, más allá de algunas acusaciones por delitos comunes, que Josué Rojas fuera realmente un bandolero.

Desde la prensa se insistió con este personaje como líder bandolero, es así que después de los sucesos del 9 de abril, el semanario El Demócrata presenta una noticia titulada "El 'Matallana' de Rondón, actúa con la pandilla" (El Demócrata, N. 50, 1948), y desarrolla la noticia diciendo que "el conocido bandolero Josué Rojas, alias -Matallana- sigue en sus gestiones criminales” (El Demócrata, N. 49, 1948).

Las gestiones criminales de que se le acusa tienen que ver con que Rojas había hecho unas acusaciones en contra del juez municipal de Rondón, diciendo que este estaba corrompiendo conciencias, haciendo protestar a ciudadanos liberales y cometiendo un cúmulo de arbitrariedades (El Demócrata, N. 49, 1948).

Hasta dónde podría tener Rojas razón frente a la actuación del juez, es algo que no se pudo discernir, pero de todas formas se exagera al calificar este hecho como una gestión criminal realizada por bandoleros. Igualmente se tilda a Rojas y a su supuesta pandilla de "ovejeros, cerderos, que arrasaron la economía de Rondón y desterraron a más de tres mil vecinos, por una ruin persecución" (El Demócrata, N. 49, 1948). Y que en un caso de que no se le castigue "habrá que hacer uso del derecho de la fuerza" (El Demócrata N. 49, 1948).

En el mismo sentido, con respecto a los liberales se usaron calificativos como gaitanistas, chusma o simplemente se les asoció con la delincuencia. Un ejemplo de este uso lo encontramos también, cuando se afirma que en el municipio de Rondón: "Con motivo de las órdenes dadas por el vesánico jefe liberal candidato de color y propulsor de la desunión liberal, (...) los gaitanistas andan por predios y veredas 
sembrando el desconcierto y propalando las ideas propias de su oligárquico jefe" ( $E l$ Demócrata, N. 49, 1948). De igual manera en Jenesano, también se denuncia a unas personas tildándolos de gaitanistas:

Jenesano, febrero 16 de 1948. Desde hace algunas semanas, un grupo de sujetos gaitanistas, encabezados por Manuel Castañeda, secretario del Juzgado Municipal, se ha dado a la tarea de irrespetar a la sociedad de este municipio, con actos que desdicen y amenguan el buen nombre de centro acogedor y pacífico de que ha gozado Jenesano por parte de los que lo visitan. Aquí en ninguna ocasión, a pesar de lo conocido de la política, se habían oído gritos y frases vulgares que hieren los oídos de la gente decente (El Demócrata, N. 35, 1948).

Se trata de un ejemplo más de cómo en este municipio de mayoría liberal, que es catalogado como un municipio pacífico, se muestran como formas de violencia los ataques verbales que eran hechos por parte de los gaitanistas a quienes se les acusa de acabar la tranquilidad del municipio con sus gritos e insultos; estas acusaciones llevarán a que efectivamente haya ataques de tipo verbal que como se verá en el cuarto capítulo, al final siempre dejaban víctimas mortales.

En el mismo sentido, se usa el término Chusma para referirse a los liberales, el cual es manejado como un sinónimo de delincuente y de persona despreciable. Por ejemplo, en Ramiriquí, en septiembre de 1948, se denuncia un intento de homicidio con el titular: "Atacado en Ramiriquí por la chusma liberal personero municipal" ( $E l$ Demócrata, N. 57, 1948), y se complementa con el subtítulo: "Se intentó ultimarlo, la enérgica actitud de este impidió que fuera ultimado" (El Demócrata, N. 57, 1948).

\section{De Kamiriquí}

ATACADO EN IRAMIRIQUI POR LA

CHUSMA LIBARAL EL PERSONERO

MUNI.IAAL.

SE INTENTO ULTIMARLO'LA ENER-

JICA ACTITUD DE EST. InPIDIO $Q$,

FUERA ULTIMDO.

Fuente: El Demócrata, N. 57, 1948.

En esta información se hace relación a seis personas que junto con otros miembros del movimiento político Jega, habrían penetrado en la Personería con el propósito de asesinar al personero, por ser el padre del teniente de la División Boyacá, Julio Olarte, sin embargo, al personero no le ocurre nada, según el diario, por su enérgica reacción. Es llamativo el hecho de que más de seis personas hayan sido dominadas 
por una sola, cuando las seis iban con la clara intención de causar un grave daño. Sin embargo, el calificativo, el estigma y el crimen asociado a este, sí irá quedando en el inconsciente colectivo, lo cual era parte de los propósitos de los conservadores, con miras a imponerse en las elecciones.

De tal manera que estos calificativos, usados para referirse a los liberales, tuvieron como único propósito acentuar el estigma de los seguidores de este partido, para que fueran vistos como un peligro para la sociedad, circunstancia que también ocurre con el "comunismo" como se ve a continuación.

\section{Liberalismo y comunismo ¿sinónimos?}

Reiteradamente se buscó hacer del comunismo un sinónimo de liberalismo, Guerrero afirma que "sin estos elementos de contexto internacional es difícil comprender la construcción de los discursos de la intransigencia, primero, y que luego desembocaron en los imaginarios irreconciliables del odio partidista" (Guerrero, 2014). Estos discursos de prevención frente al comunismo, usados desde las élites políticas, religiosas y económicas del país, también vinieron a usarse en los pequeños municipios de la provincia de Márquez, tal vez sin que los pobladores entendieran su significado, pero sí como sinónimo de un peligro que era necesario detener.

Por ejemplo, con relación a Jenesano, el semanario El Trabajo se quejaba de que: "Los policías municipales y comunistas de Jenesano amenazan nuestro semanario" (El Demócrata, 1949).

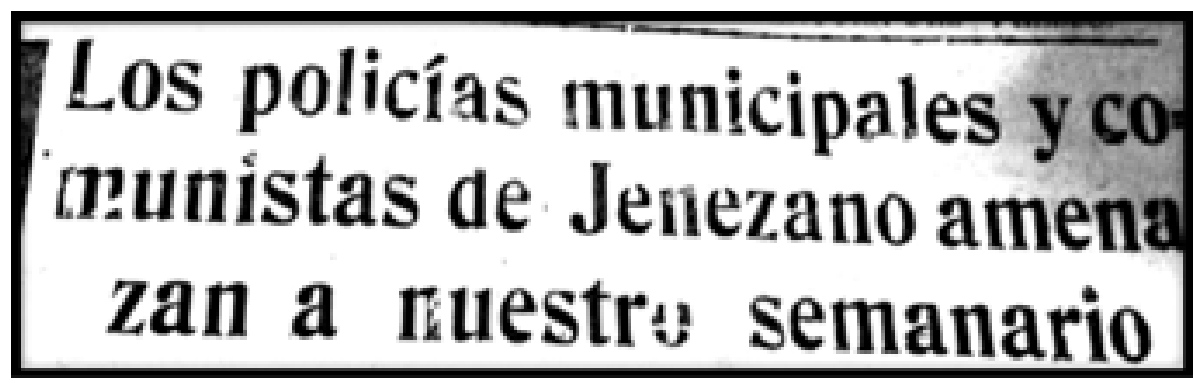

Fuente: El Trabajo, N. 103, 1949.

Luego se dice, entre otras cosas, que:

[...] nos informan de una ridícula actitud asumida por la policía municipal y el grupo sectario de comunistas de Jenesano en relación a nuestro semanario (...) El odio hacia todo lo religioso de que están animados y su torpe sentido de la vida junto con su propia ignorancia los lleva a tratar de impedir la libre circulación del periódico rodeado de sospechas y amenazas a sus propagandistas y vendedores. Se imaginarán ellos que vivimos en un 
país de esclavos y que la prensa, tribuna de la verdad, está amordazada y sometida a sus antojos (...) Ahora las cosas han cambiado. Con que, manos a la obra señores comunistas de Jenesano (El Trabajo, N. 103, 1949).

En este caso se relaciona el comunismo con la población y hasta con la misma policía, que era nombrada por el Gobierno y se les amenaza con el "nuevo orden" que en ese momento impera y, nuevamente se presenta al comunismo como un concepto contrario al de la religiosidad católica. Ahora bien, Jenesano era un municipio con mayoría liberal, de ahí el calificativo de "comunistas" que se les da a todos sus habitantes.

De otra parte, en mayo de 1948 con respecto al comunismo, pero esta vez en relación con Rondón aparece una información en la que se tilda a este municipio como "Baluarte de la legitimidad" (El Demócrata, N. 44, 1948).

La noticia hace referencia a cómo los dirigentes políticos y judiciales de Rondón lograron detener a un grupo de personas (liberales comunistas) que se cree marcharían sobre los municipios de Ramiriquí, Tunja y Bogotá. La acción realizada por los pobladores de Rondón despierta en la prensa conservadora las más altas palabras de elogio, tanto para el alcalde (militar) como hacia su autoridad judicial, pero también a sus habitantes. El siguiente es parte del relato hecho por El Demócrata:

Más de dos mil hombres se pusieron en marcha a Ranchogrande a detener a la avalancha comunista que reclutada en Zetaquira, Miraflores, Páez y otros pueblos pretendían seguir sobre Tunja. Día y noche, todo en constante vela, impidieron que la zambra comunista hiciera lo que deseaba, o sea, seguir sobre Ramiriquí para destruirlo, sobre Tunja para aniquilarla y sobre Bogotá para engrosar las huestes de Atila que todo mancharon con sus cascos impuros. Porque Rondón es la llave que cierra el paso a los afiliados de Moscú, por lo mismo debe entendérselo (N. 44, 1948).

El periódico no solo engrandece la acción de la comunidad de Rondón, sino que simultáneamente se encarga de presentar en forma muy negativa a los gobernantes y habitantes de los municipios de orientación liberal, como era Miraflores y Zetaquira; por esta razón continúa la "Oración" diciendo que:

Con alcaldes como el de Miraflores, un perdonavidas de apellido González, que amenaza, con encabezar las multitudes y sirve de parapeto a los bellacos, con un alcalde como el de Zetaquira, que solo sirve para proporcionar la impunidad de los criminales, no se puede menos que ofrendar la vida en defensa de las instituciones democráticas y eso lo hizo Rondón y hará todo sacrificio para acorralar a los bandidos que encabezan los alcaldes citados (El Demócrata, N. 44, 1948).

Mediante afirmaciones como esta, se buscaba crear en la población la prevención ante el problema que podía representar la llegada del comunismo a sus municipios, 
creando además la zozobra ante la posible invasión de un gran ejército comunista desde Zetaquira y Miraflores.

Vemos acá un claro ejemplo de violencia simbólica, pues mediante información exagerada o muchas veces falsa se busca crear un ambiente de tensión e intolerancia ante los pobladores de Jenesano, Miraflores y Zetaquira, a quienes se asimilaba con el comunismo, por hechos que nunca ocurrieron pero que tenían el propósito de deslegitimar y amedrentar a los seguidores de partido liberal, al tiempo que se generaba intolerancia y odio de parte de los conservadores hacia sus oponentes, lo cual sí dejaban víctimas por sectarismo pero en caminos o cantinas.

\section{La coacción y el constreñimiento electoral}

En conclusión, dentro del conflicto político de finales de los años cuarenta y comienzos de los cincuenta en Colombia, el propósito fundamental para los dirigentes políticos, era vencer en los procesos eleccionarios que daban acceso al poder nacional, departamental o local. Ahora bien, para la mayoría de la población el apoyo a un determinado partido, como ya se dijo atrás, estaba relacionado con la tradición, con cuestiones religiosas, de conveniencia o por la coacción.

Gerardo Molina expresa así su visión de lo que fueron los procesos de elección de a finales de los años 40:

No hay que olvidar que en el año 47, cuando Gaitán está prácticamente al frente del partido Liberal ocurrieron dos elecciones y a pesar de que sucedieron durante el gobierno conservador de Ospina Pérez, el partido liberal obtuvo la mayoría, unos doscientos mil votos aproximadamente. Entonces me parece que por la cabeza de algunos conservadores pasó la idea peligrosísima de que había que eliminar esa diferencia que favorecía al liberalismo y esa mayoría se podía eliminar de muchos modos; o bien a base de intimidación, o como también se recurrió al expediente de obligar a los campesinos principalmente, a que por medio del juramento renegaran de su fe política, a cambio de la tranquilidad para su trabajo y para su vivienda (...) De modo que eso también fue una modalidad de la violencia política. Y la modalidad peor, la más grave, fue la violencia física para eliminar a los liberales como hombres, como personas (Alape, 1987).

Lo afirmado por Molina describe de manera concreta lo que en general se vivió en Colombia en relación con las dinámicas electorales y el conflicto bipartidista a finales de la década de los cuarenta, ya que el partido conservador, hizo uso de diferentes formas de coacción para buscar imponerse en las elecciones.

Así como a nivel nacional el partido conservador hizo uso de estrategias, que iban más allá de la campaña política, o la defensa de unos ideales, estas estrategias también fueron puestas en práctica en la provincia de Márquez, con algunas particularidades. La siguiente tabla muestra resultados de las votaciones entre 1946 y 1949; los de 1946 corresponden a las elecciones presidenciales y los de 1947 y 1949 corresponden a las 
elecciones para Cámara de Representantes, teniendo en cuenta que en las elecciones presidenciales de 1949 el partido Liberal se abstuvo de participar:

Tabla 2. Resultados electorales en los municipios de la provincia de Márquez 1946, 1947 y 1949

\begin{tabular}{|c|c|c|c|c|c|c|c|}
\hline \multirow{3}{*}{ MUNICIPIO } & \multicolumn{3}{|c|}{ PRESIDENCIALES } & \multicolumn{4}{|c|}{ REPRESENTANTES A LA CÁMARA } \\
\hline & 1946 & 1946 & 1946 & $\begin{array}{c}\text { Marzo } \\
1947\end{array}$ & Marzo 1947 & $\begin{array}{c}5 \mathrm{de} \\
\text { junio de } \\
1949\end{array}$ & $\begin{array}{c}5 \text { de junio de } \\
1949\end{array}$ \\
\hline & Turbay & Gaitán & Ospina & Liberal & Conservador & Liberal & Conservador \\
\hline Ciénega & - & - & - & 15 & 474 & 0 & 713 \\
\hline Ramiriquí & 190 & 199 & 166 & 409 & 662 & 0 & 2259 \\
\hline Rondón & - & - & - & 257 & 161 & 0 & 1048 \\
\hline Tibaná & 717 & 0 & 5 & 1458 & 54 & 1801 & 24 \\
\hline Úmbita & 89 & 6 & 961 & 48 & 114 & 0 & 1666 \\
\hline Viracachá & 112 & 47 & 261 & 99 & 418 & 1 & 893 \\
\hline $\begin{array}{l}\text { Total provincia de } \\
\text { Márquez }\end{array}$ & 1.190 & 488 & 1.393 & $\begin{array}{c}2.807 \\
59 \% \\
\end{array}$ & $\begin{array}{l}1.907 \\
41 \% \\
\end{array}$ & $\begin{array}{l}2.852 \\
31 \% \\
\end{array}$ & $\begin{array}{c}6.616 \\
69 \% \\
\end{array}$ \\
\hline $\begin{array}{l}\text { Total Dpto. } \\
\text { Boyacá }\end{array}$ & 35.016 & 11.301 & 32.655 & $\begin{array}{l}43.962 \\
42.8 \%\end{array}$ & $\begin{array}{c}58.668 \\
57 \%\end{array}$ & $\begin{array}{l}45.652 \\
31.9 \%\end{array}$ & $\begin{array}{c}97.258 \\
68 \%\end{array}$ \\
\hline
\end{tabular}

Fuente: Junco (1992) y Rojas (1992).

De acuerdo con los resultados electorales de la provincia de Márquez, que muestra la tabla 2, en 1946, para las elecciones presidenciales el voto liberal, sumando los resultados de Turbay y Gaitán, representa el 54\% contra el $46 \%$ de votos conservadores, mientras que en 1947 en las votaciones para Cámara, el partido Liberal obtiene el 59\% de los votos contra el $41 \%$ de votos conservadores. Ahora bien, de acuerdo con Gerardo Molina, es a partir de estos resultados que el conservatismo, que tenía el poder ejecutivo pero no el legislativo, que se propone una serie de estrategias para cambiar esta circunstancia; tal es así que en las elecciones de junio de 1949 la proporción cambia abruptamente, pues el partido Conservador obtiene en la provincia de Márquez el 69\% de los votos contra el 31\% que obtienen los liberales, con mayorías absolutas en Ramiriquí, Rondón, Úmbita, Ciénega, Viracachá. Solo en Tibaná y Jenesano el partido Liberal tendrá una abrumadora mayoría. Estos resultados serán muy parecidos a los que presentó en general el departamento de Boyacá. ¿Cómo se explica un cambio tan drástico en tan solo dos años de un proceso a otro? Pareciera que las estrategias utilizadas y anunciadas en párrafos anteriores daban sus resultados, que como ya se afirmó, tenían que ver con la violencia simbólica o con la violencia física. Veamos cómo se manejaron estas estrategias en la provincia: Lo primero que aparece es la mano de la Iglesia tomando 
partido y llevando a la población a tomar partido. Algunos mensajes utilizados para tal fin decían: "La Santa Sede prohíbe votar por los comunistas y los izquierdistas comunistoides" (El Trabajo, N. 57, 1948); en 1949 “Monseñor Perdomo prohíbe votar por candidatos abrileños liberal comunistas. Traición a los dictados de la conciencia y de la patria sería votar por los de abril" (El Trabajo. N. 57, 1948). Esta prohibición desde la Iglesia, buscaba usar los sucesos del 9 de Abril como una forma de manipular a los liberales, haciéndolos responsables, primero, del asesinatos de Gaitán y, luego, de los muertos y la destrucción fruto de la reacción ante este hecho, asimilándolos igualmente al comunismo.

En Boyacá, y en particular en la provincia de Márquez, una estrategia que se usó mucho, a parte de la manipulación religiosa, aunque apoyada en esta, fue la de la "Protesta", que consistía en que a las personas que fueran liberales se les amenazaba o se les hostigaba para que se vieran obligados a cambiar de partido, lo cual se hacía por medio de un documento o certificado que decía que "fulano de tal" se había cambiado de liberal a conservador, por lo cual ya no sería molestado y en cambio sí podría votar por candidatos conservadores. Estos hechos se acompañaban de la publicidad, asegurando que se trataba de una desbandada de liberales hacia el partido Conservador como se ve en el siguiente titular" (El Demócrata, N. 43, 1948).

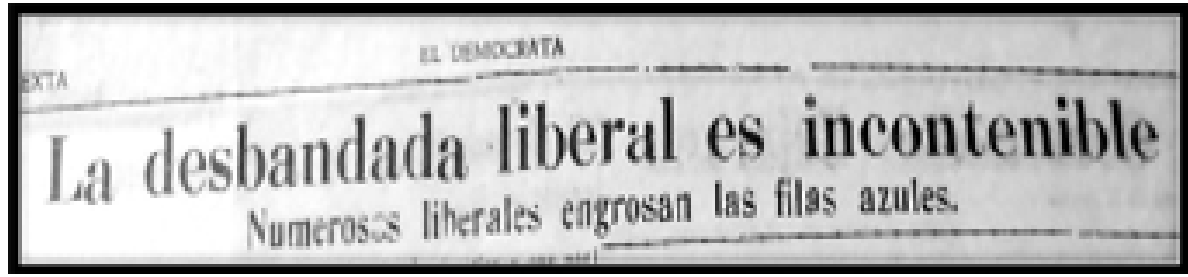

Fuente: El Demócrata, N. 43, 1948.

Con respecto a los municipios de la provincia de Márquez, el semanario $E l$ Demócrata reseña lo siguiente: "Protestas liberales en Rondón. Liberales sensatos continúan adhiriéndose al partido conservador. Principales motivos: horrendos y criminales acontecimientos del 9 de abril y la defensa de la religión católica, de la patria y de sus hogares" (El Demócrata, N. 43, 1948). Estos dos argumentos fueron los más usados como motivos para el cambio de partido. El primero relacionado con el asesinato de Gaitán en Bogotá en abril de 1948, pues, desde el conservatismo se insistió en la versión de que el asesinato de Gaitán había sido planeado y ejecutado por los comunistas, al tiempo que los liberales eran culpables de la destrucción y de los muertos que produjo la reacción popular, por lo que se quiso asociar a los liberales en general con los sucesos del 9 de abril, por lo que se les invitaba a arrepentirse de esta circunstancia, con lo que una forma de reivindicarse, era cambiándose del partido liberal al partido conservador. El otro elemento que se usó corresponde a la religiosidad católica de muchos liberales a quienes se buscaba reaccionaran con 
toda esta carga de mensajes de culpabilidad, pues como ya se ha dicho, el pertenecer al partido liberal era asociado con el comunismo y este con el ateísmo y con la persecución a la Iglesia, con la destrucción de la patria y de la familia, con lo cual se recalcaba en el hecho de que pertenecer al partido liberal era ir en contra de la religión de Cristo y por lo tanto un pecado grave.

Como se mencionó, la protesta, fue una de las prácticas más palpables para conseguir el cambio de partido. Los siguientes relatos muestran cómo se llevó a cabo en algunos municipios de la provincia:

En el caso de Úmbita, un municipio de mayoría conservadora, las siguientes protestas permiten ver los elementos que se tenían en cuenta para llevar a las personas a esta decisión:

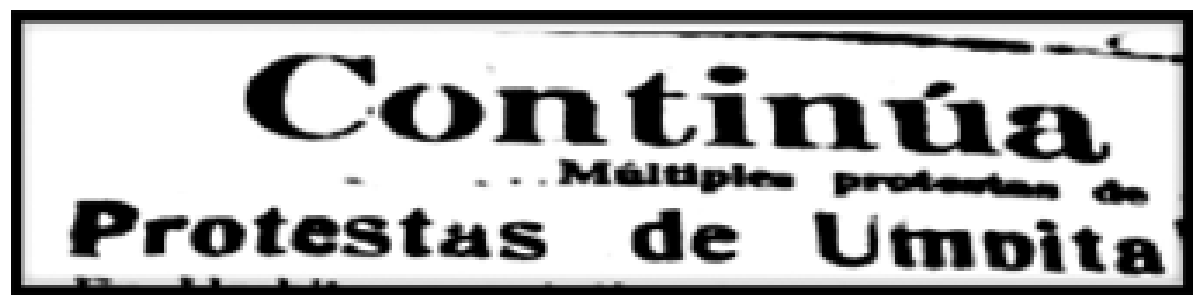

Fuente: El Demócrata, N. 69, 1949.

Protesta en Úmbita.

Yo, Pedro Nel Soler, ciudadano colombiano y vecino de este municipio, estando en pleno uso de mis facultades y convencido como católico, apostólico y romano, de que las doctrinas liberales pugnan abiertamente contra los principios católicos y contra las enseñanzas de los pontífices romanos, y que yo he nacido en el seno de la iglesia católica y profesado sus doctrinas, para no estar en desacuerdo con mi conciencia aparentando una cosa que no soy ni profeso, bajo la gravedad de juramento, PROTESTO solemnemente de las doctrinas liberales y de todos sus errores condenados por la iglesia en cuyo seno quiero vivir y morir. Reafirmo, pues, que en adelante militaré en las filas conservadoras por ser este partido de orden y de paz. En constancia de lo expuesto firmo esta protesta sin ser compelido por nadie, ante testigos [...] (El Demócrata, N. 69, 1949).

En esta acción, se ve nuevamente el uso de la Fe, como argumento de gran validez para persuadir u obligar a una persona cambiarse del partido liberal al partido conservador, el cual era el partido que defendía la "Fe de Cristo", el partido del "orden y la Paz", y aclarando al final que se hace voluntariamente, afirmación bastante dudosa.

Resalta de estas "protestas" la disposición a defender al partido conservador en toda circunstancia, pues de lo contrario nuevamente eran amenazados con penas de 
carácter religioso; y más que un cambio voluntario, lo que demuestra este cambio de partido a través de documento público es el poder del partido Conservador y de la Iglesia para constreñir a las personas en búsqueda de propósitos electorales, en un claro ejemplo de "violencia simbólica".

La otra forma utilizada frecuentemente para alterar la voluntad de los ciudadanos y lograr mayorías del partido conservador, y que forma parte de las expresiones de la violencia simbólica hace relación a la práctica de impedir que los hombres liberales fueran a las urnas a votar por su partido, mediante el decomiso o la retención de su cédula. Frente a este caso, el señor Ezequiel Nope asegura que en época de elecciones, en los días previos a estas, durante las confesiones católicas a las cuales acudía un gran número de mujeres, los sacerdotes les preguntaban a qué partido político pertenecía su esposo y si este era liberal, les imponía como penitencia de sus "pecados" traer la cédula de sus conyugues al sacerdote, el cual las guardaba hasta que pasaran dichos procesos eleccionarios, para luego devolvérselas, de tal manera que cuando ellos iban a votar no encontraban la cédula por ninguna parte y aunque sus esposas les contaran lo ocurrido, el respeto que en general había o se debía tener a los sacerdotes, llevaban a tener que aceptar este hecho (entrevista a Nope, Ezequiel, 2016).

En febrero de 1949, se resalta una información según la cual, se estaban introduciendo armas de manera clandestina en el departamento de Boyacá y se resalta que:

Gran número de armas decomisadas al liberalismo. El liberalismo se prepara en forma violenta para el próximo debate electoral (...) en el municipio de Ciénega, donde el señor alcalde, asesorado de la policía municipal decomisó algunas de esas armas que habilidosamente portaban verdaderos bandoleros (...) como lo son Carlos Barrera, Guillermo Barrera y otros célebres por sus antecedentes delictuosos. Fueron decomisadas pistolas ametralladoras. Prueba de la manera en que el liberalismo se prepara en forma violenta contra el partido conservador y contra el gobierno. Felicitan al alcalde y a la policía por frustrar los terroríficos planes del adversario sanguinario ( $E l$ Demócrata, N. 72, 1949).

De acuerdo con esta información, dentro del liberalismo habría una organización y unos planes para, por medio de la violencia, ganar las elecciones, para los cual se estaban llevando armas a este municipio. Sin embargo, es llamativo que en los resultados electorales del 5 de junio de ese año, en Ciénega habrá cero votos liberales contra 713 votos conservadores. Esto quiere decir que los "Terroríficos" planes del liberalismo no ayudaron para conseguir ni un solo voto, mientras que las estrategias conservadores obtuvieron en Ciénega el $100 \%$ de los votos. Esto indica que, o era mentira lo de los planes terroríficos o no eran tan terroríficos como se los quería hacer ver. Además, un resultado como este, el cual también se presentó en Ramiriquí, Úmbita, Rondón, indica el uso de algo más que el simple proselitismo político. 
En el mismo orden, un periódico conservador en febrero de 1949, afirmaba que

El conservatismo de la provincia de Márquez está en pie para ganar las elecciones de los concejeros municipales. Se da como un hecho seguro que el partido pondrá mayoría en los concejos de Ramiriquí, Ciénega, Viracachá, Rondón, Úmbita y Boyacá, es decir en 7 de los 9 municipios de la Provincia (El Demócrata, N.72, 1949).

Y efectivamente en estos municipios obtuvieron mayorías abrumadoras, de lo cual se colige que estos resultados obedecen a estrategias que no se basaron únicamente en el fraude sino que "una serie de factores amparados en el poder, se conjugaron para cambiar la balanza entre los partidos tradicionales, esta vez en favor del partido conservador" (Junco, 1992).

En este sentido, es importante recordar la tesis de Gladys Rojas de Segura según la cual, el Directorio Nacional Conservador tuvo como propósito, apoyándose en líderes departamentales, conservatizar a Boyacá, mediante una acción ideológica, una acción político militar y de bandas para-institucionales, lo cual sería un experimento para luego extender este propósito a todo el país, emulando lo hecho en España por parte de los franquistas (Rojas, 1992).

\section{CONCLUSIONES}

Dentro de las diferentes manifestaciones de violencia que se dieron en el conflicto bipartidista de mediados del siglo XX, lo que se ha denominado violencia simbólica jugó un papel preponderante como instrumento de hostilidad y manipulación de quienes detentaban el poder. El partido conservador se valió del uso de la información, los discursos, la Fe católica, los estigmas políticos y el dominio sobre las entidades estatales, para manipular o coaccionar al electorado, para lograr imponerse en las elecciones y así obtener un mayor control del Estado. Dentro de este propósito, se hizo uso de la información que era propagada por la prensa, con el fin de hacer señalamientos insistentemente, que pusieran en tela de juicio la legitimidad del partido liberal y sobre todo de quienes lo apoyaban, buscando que estos terminaran por renunciar a este partido para unirse al partido conservador. Muchos de estos señalamientos estaban asociados con la religión católica, pues se hacía ver que quienes pertenecieran al partido liberal eran enemigos de la iglesia y de la Fe de Cristo, llegando inclusive a declarar como pecado grave, el hecho de votar por candidatos liberales.

De igual manera, a los liberales se les asoció con diferentes conceptos que a su vez eran vistos como algo negativo o perjudicial. Dentro de estos, el concepto con que más se buscó estigmatizar a los liberales fue con el de "Comunista", haciéndolo ver como una ideología extranjera que perseguía a la Iglesia católica y que conllevaba al desorden y la inseguridad social, económica y moral. También el Gobierno creó 
sindicatos católicos con el fin de debilitar a los sindicatos tradicionales con miras a frenar el movimiento obrero asociado al liberalismo.

Todas estas formas de violencia se manifestaron en los municipios de la provincia de Márquez, buscando el mismo propósito, vencer en las elecciones de 1949. Los resultados electorales muestran que con excepción de Jenesano y Tibaná, en los demás, el partido conservador logró una arrasadora victoria, valiéndose entre otras cosas, de las "Protestas" mediante las cuales los liberales, ante la hostilidad de los gobernantes locales, de la iglesia y de la información, terminaban por cambiarse de partido, para apoyar al partido conservador; además, también se buscaron formas para no permitir que los liberales votaran, como fue el caso de la confiscación de la cédula por parte de los sacerdotes como penitencia por los pecados.

\section{REFERENCIAS}

Acuña, O. (2000). Campañas políticas electorales. Boyacá 1930-1953. Trabajo de grado, Maestría en Historia, UPTC.

Alape, A. (1987). El Bogotazo: Memorias del olvido (p. 139). Bogotá: Editorial Planeta.

Archivo Departamental de Boyacá. El Boyacense, 1946-1953.

Contraloría General de la República, Dirección Nacional de Estadística. (1952). Censo General de Población de1951. Departamento de Boyacá, Tomo IV. Bogotá: Imprenta Nacional.

El Demócrata. (1947). Números: 16, 28. Fondo Hemeroteca, Archivo Regional de Boyacá ARB.

El Demócrata. (1948). Números: 35, 37, 43, 44, 48, 49, 50, 57,62. Fondo Hemeroteca, Archivo Regional de Boyacá ARB.

El Demócrata. (1949). Números: 69, 72, 103. Fondo Hemeroteca, Archivo Regional de Boyacá ARB.

El Demócrata. (1950). Número 95. Fondo Hemeroteca, Archivo Regional de Boyacá ARB.

El Demócrata. (1953). Número 151. Fondo Hemeroteca, Archivo Regional de Boyacá ARB.

El Trabajo. (1948). Números 47, 57. Fondo Hemeroteca, Archivo Regional de Boyacá ARB.

El Trabajo. (1949). Número 103. Fondo Hemeroteca, Archivo Regional de Boyacá ARB.

Entrevista a Nope Cruz Ezequiel. Tibaná, diciembre 27 de 2016.

Expediente 2770 (1950). Caja 210. Archivo Judicial de Tunja.

Foucault, M. (1992). Genealogía del racismo. De la guerra de las razas al racismo de Estado. Madrid: Ediciones La Piqueta. 
Guerrero, J. (2014). El proceso político de las derechas en Colombia y los imaginarios sobre las guerras internacionales 1930-2945 (pp. 150, 440, 464). Tunja: Ed. UPTC.

Junco, E. (1992). Del fraude y la violencia al clientelismo, Boyacá 1930-1990 (pp. 97, 103 y 174). Tunja: UPTC.

Oquist, P. (1978). Violencia, conflicto y política en Colombia (pp. 229, 248). Bogotá: Instituto de Estudios Colombianos.

Pulido, A. (2010). Ramiriquí en el Bicentenario. Tunja: Ed. Salamandra.

Rojas, G. (1992). La violencia en Boyacá 1946-1950. Protagonismo político del Directorio Departamental Conservador (p. 11). (Trabajo de Grado Maestría en Historia UPTC).

Sánchez, G. y Meertens, D. (1983). Bandoleros, gamonales y campesinos: El caso de la violencia en Colombia. Bogotá: El Ancora. 